\title{
A visão de moral dos profissionais de uma unidade básica de saúde e a humanizaçãa ${ }^{*}$
}

\author{
José Roque Junges ${ }^{1}$ \\ Rafaela Schaefer ${ }^{2}$ \\ Jessica Prudente ${ }^{3}$ \\ Raquel Elisa Ferreira De Mello ${ }^{4}$ \\ Cassiane Silocchi ${ }^{5}$ \\ Marielli de Souza ${ }^{6}$ \\ Guilherme Wingert ${ }^{7}$
}

JUNGES, J.R. et al. The moral vision of professionals at a primary healthcare unit and humanization. Interface - Comunic., Saude, Educ., v.15, n.38, p.755-62, jul./set. 2011.

The aim of the study was to analyze the moral vision of professionals working in a primary healthcare unit and to indicate its implications for the strategy of humanization of healthcare. This was an investigation of exploratory nature with a qualitative approach. Data were gathered at a primary healthcare unit and were subsequently interpreted using discourse analysis. The professionals perceived morality as having good intentions in the care provided, such that the results are more a consequence of technical procedures than an ethical issue. The guidelines for the National Humanization Policy propose co-responsibility and comanagement among healthcare professionals, managers and users, in order to achieve the objectives of humanization, problem-solving and excellence in healthcare provision. In conclusion, if humanization is not a matter of charity, but rather a fulfillment of user rights, professional ethics should not depend on good intentions but be based on results that are identified with responsibility.

Keywords: Ethics. Morality. Primary Health Care. Humanization of care. Social responsibility.
A proposta deste estudo foi analisar a visão moral dos profissionais de uma Unidade Básica de Saúde (UBS) e apontar suas implicações para a estratégia da humanização da assistência. Trata-se de uma investigação de natureza exploratória, com abordagem qualitativa. Os dados foram coletados em uma UBS e, posteriormente, interpretados pela análise do discurso. Os profissionais identificam moral como ter boas intenções no atendimento, sendo os resultados mais uma consequência de procedimentos técnicos do que uma questão ética. As diretrizes da Política Nacional de Humanização propõem a corresponsabilidade e a cogestão de profissionais, gestores e usuários, para o alcance dos objetivos da humanização, da resolutividade e da excelência na prestação dos serviços de saúde. A humanização não é uma questão de caridade, mas corresponde à realização dos direitos do usuário; a ética do profissional não pode estar pautada pela boa intenção, deve ser baseada nos resultados, identificando-se com a responsabilidade.

Palavras-chave: Ética. Moral. Atenção Primária á Saúde. Humanização da assistência. Responsabilidade social.
Fontes financiadoras Edital MCT/CNPQ/ MS-SCTIE-DECIT N.023/2006.

1.7 Programa de Pós-Graduação em Saúde Coletiva, Universidade do Vale do Rio dos Sinos (UNISINOS). Caixa Postal 101 (UNISINOS), São Leopoldo, RS, Brasil. 93.001-970.

jrjunges@unisinos.br 


\section{Introdução}

A Política Nacional de Humanização (PNH) perpassa todos os processos e atores envolvidos no Sistema Único de Saúde (SUS), visando desfragmentar e desverticalizar os processos de trabalho na construção coletiva de saúde. A humanização é o eixo da ética nas práticas de saúde, pois propõe movimentos instituintes de crítica e problematizações constantes acerca dos processos em saúde. A percepção dos profissionais sobre moral na humanização interfere nas relações pessoais, nos processos de trabalho e na gestão, estando diretamente ligada ao que é produzido na prática profissional. Assim, faz-se importante diferenciar entre o instituído como prática corrente e o instituinte como análise crítica correspondente aos conceitos de moral e de ética, a fim de contextualizar a discussão deste estudo (Brasil, 2004).

Segundo Cortina e Martinez, 2005, "moral" é o conjunto de princípios, normas e valores que cada geração transmite à geração seguinte na confiança de que se trata de um bom legado de orientações sobre o modo de se comportar para viver uma vida boa e justa. Nesse sentido, a moral está ligada à vida prática, influenciando comportamentos e atitudes, em um sentido mais geral. Em contrapartida, a moralidade compõe a vivência subjetiva da moral de forma mais particular. Já a "ética" é a disciplina filosófica que constitui uma reflexão de segunda ordem sobre os problemas morais, ou seja, pressupõe crítica e reflexão sobre tais problemas. Dessa forma, as reflexões dos profissionais acerca da moralidade de suas práticas e ações determinam o modo de entender a humanização.

Além dessa distinção, é importante, para a discussão sobre a prática de humanização, a diferença proposta por Weber, 2003, entre ética da convicção e ética da responsabilidade. A primeira está baseada em ações bem-intencionadas, tirando do sujeito a responsabilidade dos resultados, já que o que interessa é a manutenção da pureza da doutrina. Por sua vez, a ética da responsabilidade pressupõe um sujeito que deve se responsabilizar pelas consequências de suas ações. Por isso, segundo Weber (2003, p.94):
A ética absoluta é imune às consequências. Essa é a questão decisiva. Há um contraste abismal entre a ação resultante da ética atemporal que visa aos fins - isto é, em termos religiosos, "O cristão age com retidão e deixa os resultados nas mãos do Senhor" - e a ação resultante da ética da responsabilidade, na qual se deve prestar conta das consequências previstas das próprias ações.

Para a humanização, entendida como ética dos serviços de saúde, é importante conhecer qual é a visão moral dos profissionais e analisá-la eticamente a partir da compreensão de Weber. A visão moral dos profissionais pesquisados foi construída no contexto da discussão sobre humanização. Nesse sentido, a humanização servirá, também, como referência para análise da visão moral dos profissionais. A humanização estabelece-se como a construção/ativação de atitudes ético-estético-políticas em sintonia com um projeto de corresponsabilidade e qualificação dos vínculos interprofissionais e entre estes e os usuários na produção da saúde. Éticas porque a defesa da vida constitui o eixo de suas ações. Estéticas porque estão voltadas para os processos de invenção das normas que regulam a vida. Políticas porque é na relação entre os homens que se operam as relações sociais e de poder (Brasil, 2004).

Destaca-se que, na literatura, encontram-se muitos estudos que refletem a ética acerca da humanização na realidade hospitalar, pois o contexto de gravidade e as situações-limite predispõem a uma evidência dessas questões. Entretanto, o trabalho em atenção primária também representa uma realidade complexa, mas a escassez de estudos desta temática reflete a visão hospitalocêntrica ainda presente na cultura da maioria das pessoas.

O objetivo do artigo é analisar a visão moral dos profissionais de uma Unidade Básica de Saúde (UBS) e apontar suas implicações para a estratégia da humanização. 


\section{Metodologia}

O presente artigo é fruto da pesquisa "O discurso dos trabalhadores de uma Unidade Básica de Saúde (UBS) em São Leopoldo (RS) sobre a humanização dos serviços", inserida na linha de pesquisa "Vulnerabilidade em Saúde e Bioética" do Programa de Pós-Graduação em Saúde Coletiva da Universidade do Vale do Rio dos Sinos. Trata-se de uma pesquisa exploratória com abordagem qualitativa, cuja coleta de dados realizou-se através de grupos focais. A partir do contato com a Secretaria Municipal de Saúde, a UBS da Vila Campina foi indicada como local apropriado para os objetivos da pesquisa. O projeto de pesquisa foi aprovado pelo CEP da Unisinos.

O universo empírico da pesquisa foi definido intencionalmente, tendo presente as diferentes competências profissionais e o maior tempo de serviço na unidade. O grupo focal era integrado por uma médica ( $M$ ), um dentista (D), dois enfermeiros/as (E1 e E2), três técnicos/as de enfermagem (T1, T2 e T3), um atendente da portaria (P), um encarregado do almoxarifado (A) e a gestora da unidade $(G)$, totalizando dez participantes escolhidos entre os cerca de sessenta que atuam na unidade, mais o pesquisador/facilitador (F) da discussão focal. Foram feitas oito reuniões, de uma hora e meia cada, com o mesmo grupo, sobre diferentes aspectos da humanização, como: direito à saúde, subjetividade, integralidade, acolhimento, resolubilidade, responsabilidade, intersetorialidade e suas interfaces com o cotidiano dos profissionais. As interações e discussões foram digitalmente gravadas e o texto transcrito foi trabalhado e interpretado através da metodologia da análise discursiva.

Esse tipo de análise é o mais adequado quando se trata de interações discursivas de um grupo focal organizado em vista de um objetivo, como é o caso de profissionais de uma unidade básica. Não seria pertinente fazer entrevistas individuais com os trabalhadores e depois analisá-las pelo método de análise de conteúdo, porque não interessam os significados dados por cada um à humanização, mas sim o discurso sobre esta temática que surge na interação entre os participantes da discussão. A realidade da humanização não existe independente das interações que acontecem na unidade, portanto, ela só está presente no discurso que acontece nessas interações. Em outras palavras, a realidade é continuamente construída pelo discurso e está presente no discurso. Isso significa assumir uma visão pragmática da linguagem, porque a linguagem é ação e o seu significado depende essencialmente do contexto (Rueda, 2003; Potter, Wetherell, 2002; Austin, 1998).

A análise do discurso não trabalha com a codificação em categorias temáticas, como é o caso da análise de conteúdo, mas em repertórios interpretativos que são conjuntos de diálogos interativos que tecem discursivamente a realidade. A partir da análise da transcrição de um dos grupos focais, surgiram repertórios interpretativos a respeito da humanização, relacionados à moral.

\section{Resultados e discussão}

No discurso dos profissionais emergem duas principais concepções acerca da moral: a primeira é a de que uma atitude moral consiste em ter boas intenções; a segunda é a de que o importante são os resultados, independentemente das intenções. Dessa forma, há uma alternância no discurso do grupo entre agir conforme suas intenções e agir responsabilizando-se pelos resultados da ação, prevalecendo uma percepção de moral baseada em princípios e convicções, independente dos resultados. Faz-se necessário realizar uma análise ética sobre a moral, utilizando-se os pressupostos da ética da convicção e da ética da responsabilidade segundo Weber, 2003. Assim, a moral baseada na intenção, corresponde à ética da convicção, e a moral baseada nos resultados corresponde à ética da responsabilidade.

No levantamento dos resultados, foram encontrados alguns repertórios sobre a moral em sua relação com a Política Nacional de Humanização (PNH). Para analisar as falas discursivas, parte-se de uma visão pragmática, que define a linguagem como ação. As pessoas que fizeram parte dos grupos focais estão agindo ao falarem, construindo sua realidade no discurso.

O primeiro repertório analisado expressa os significados dados pelos profissionais em relação à moral, entendida como boa intenção ou consequência. O repertório abaixo foi construído no oitavo grupo focal no momento em que os participantes foram incentivados a discutir sobre a Humanização 
como eixo da ética nos serviços de saúde. A partir destas interações discursivas, apareceu o seguinte diálogo:

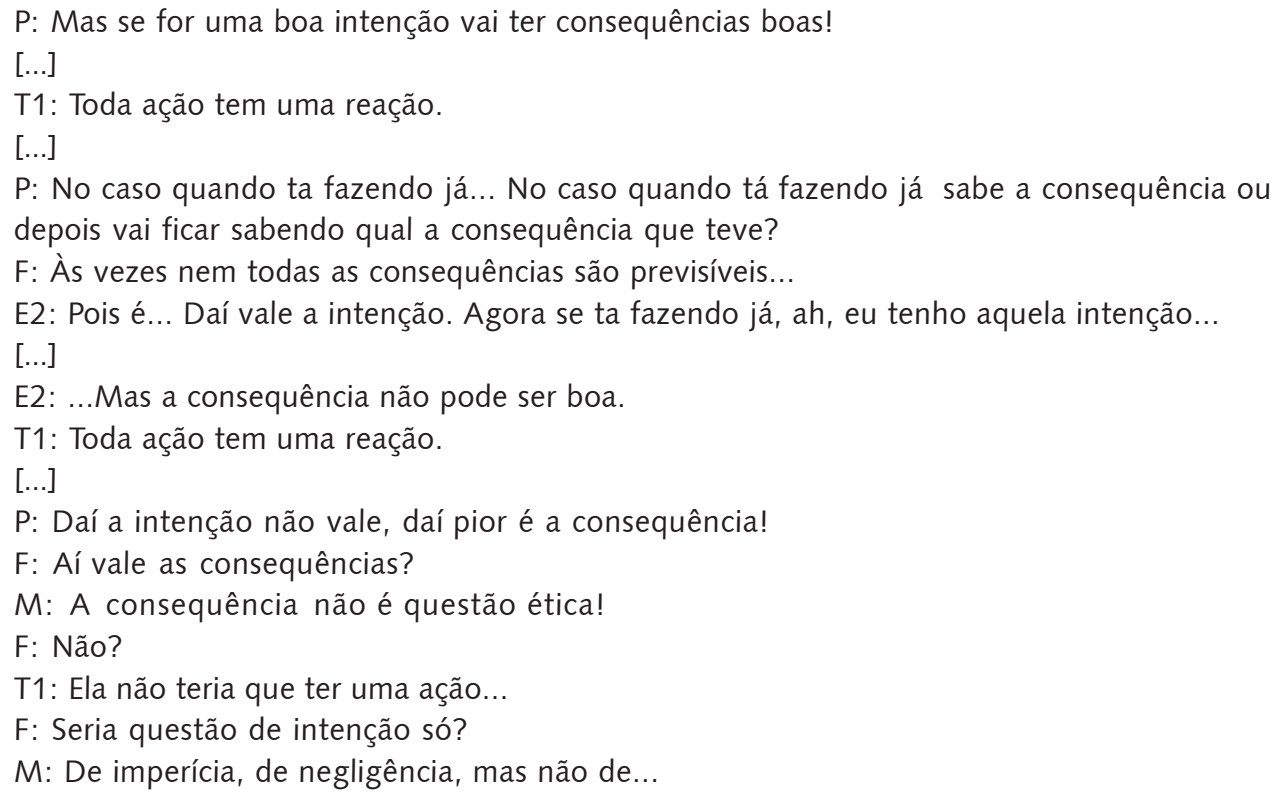

A análise do discurso traz os deíticos de pessoa (pronomes pessoais) que situam o contexto de enunciação do discurso (Rueda, 2003). Neste repertório estes deíticos não são referidos, revelando um discurso impessoal, que (des)implica o sujeito. As falas são abstratas, não explicitando o sujeito da ação, nem individual, nem coletivo. Dessa forma há uma ênfase no contexto do discurso, e não nos agentes responsáveis pelos processos, e uma desresponsabilização do profissional de saúde.

Uma das diretrizes da PNH afirma que, para que se possa reforçar o conceito de clínica ampliada, essencial para a efetivação do atendimento em atenção primária, é necessário que haja um compromisso do profissional com o sujeito e seu coletivo, bem como a corresponsabilidade de todos os atores envolvidos no processo de produção de saúde (Brasil, 2004), o que se apresenta em dissonância com o repertório descrito acima.

Para a compreensão deste repertório, é importante referir mais um dos elementos da análise do discurso, a indexicabilidade. Ela explica o contexto da enunciação, revelado neste repertório a partir de falas gerais sobre as ações e suas consequências, apresentando contradições no discurso. A enunciação sempre acontece num contexto que fornece o significado específico da palavra. Por isso, é necessário analisar o contexto para entender o que é dito (Rueda, 2003).

O contexto da Unidade Básica de Saúde pesquisada apresenta uma condição estrutural específica: ela engloba, além dos cuidados primários, a emergência e o agendamento de especialidades, sobredeterminando a demanda. Além disso, devido ao excesso de demanda, ambiente físico reduzido e ausência de reuniões de equipe, não há uma reflexão sobre os problemas e os desafios da unidade. Tais reuniões poderiam compor um momento de construção dos sujeitos de saúde (usuários e profissionais) e permitir a execução de uma das diretrizes da $\mathrm{PNH}$, que prega o diálogo permanente entre os atores presentes no contexto assistencial, promovendo a gestão participativa (Brasil, 2004). Dessa forma, constitui-se um ambiente pautado na execução individual de cada função, isolada do todo, fato este que será explicitado na análise discursiva a seguir.

O que eles estão fazendo ao falar? O discurso revela uma antecipação defensiva para possíveis consequências indesejadas, pois eles enfatizam que as suas práticas profissionais estão baseadas na ética da convicção, ou seja, da boa intenção. Essa postura discursiva se relaciona com a realidade do cotidiano e com os processos de trabalho centrados nos procedimentos e técnicas, bem como na formação centrada no fazer de cada especialidade. $\mathrm{O}$ apego aos procedimentos e protocolos na discussão 
subjetiva acaba levando a compreensão para o lado prático, o que acarreta falta de clareza no discurso. Além disso, a falta de um coletivo formado, que se comunica e traça objetivos em comum, reforça essa individualização, através da ausência de corresponsabilidade e cogestão.

A contraposição weberiana entre a ética de convicção e a ética de responsabilidade fica evidenciada no momento em que alguns profissionais afirmam a ideia de que, necessariamente, boas intenções acarretam "boas" consequências. Esta fala deixa de lado a dimensão da responsabilização pelo processo de cuidado como um todo. Ainda, neste repertório, é afirmado que: "a consequência não é questão ética [...], mas de imperícia, de negligência [...]". Tal observação demonstra uma visão de que as consequências da ação têm relação com procedimentos técnicos das ações em saúde, e não com uma postura ética.

O próximo repertório tem como temática predominante uma falta de diferenciação entre normas/ regras e valores pessoais, pois há uma alternância no discurso que evidencia um entendimento conflituoso entre os conceitos. Parte-se do pressuposto de que normas referem-se a noções de boa educação e etiqueta, constituindo regras de convivência grupal que cada indivíduo deve seguir. Já os valores, segundo Cortina e Martinez, 2005, constituem atitudes que pautam comportamentos que estão baseados no ethos coletivo de uma comunidade. Nesse contexto aparece o seguinte diálogo:

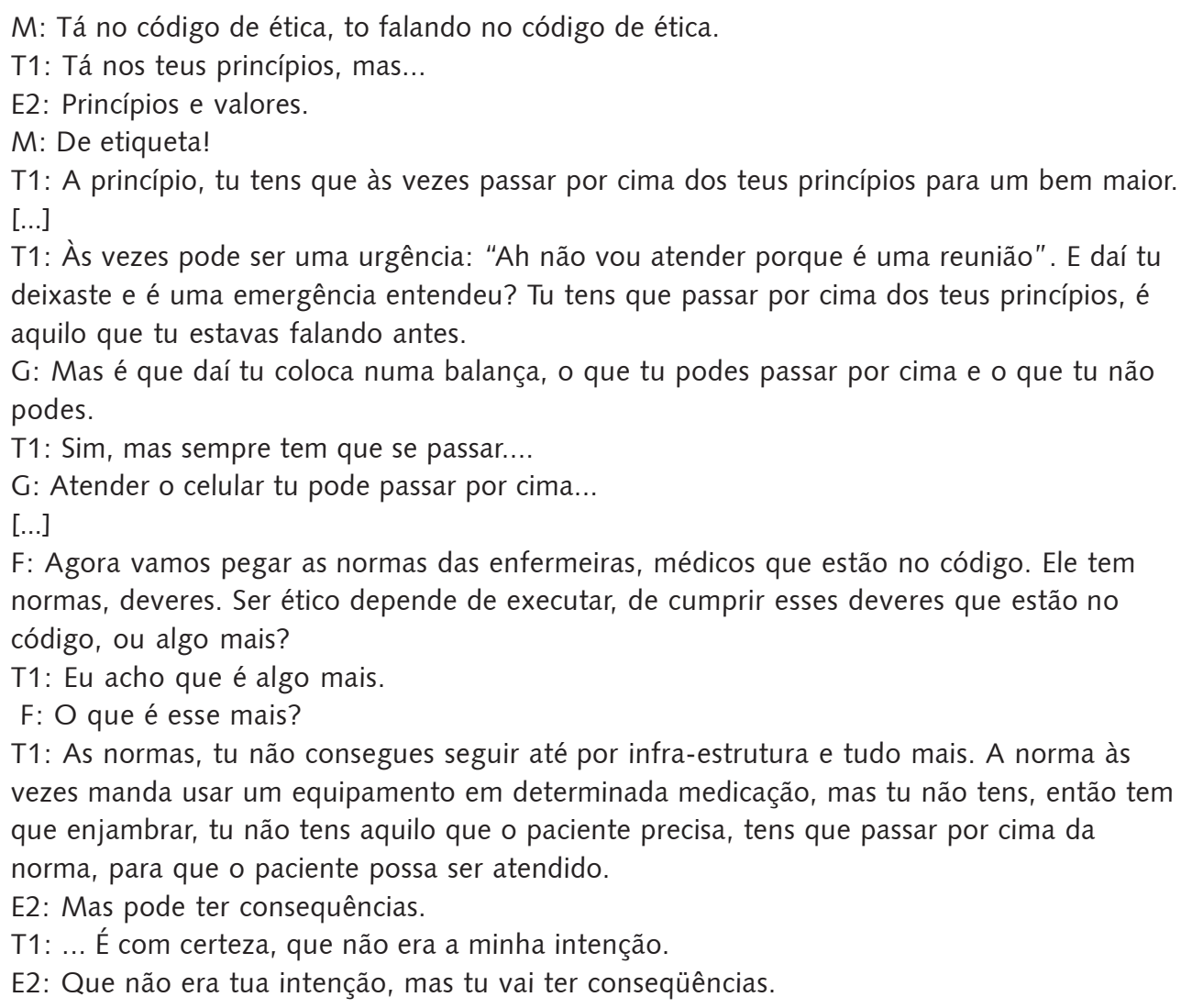

A falta de diferenciação entre princípios e normas fica explícita nas falas do repertório, pois os profissionais vão intercalando conceitos de maneira indiscriminada, ora referindo-se ao código ético, ora referindo-se a valores e princípios, para nomear a mesma ação, como se uma concepção se articulasse com a outra. Essa indiferenciação é demonstrada, também, quando os profissionais referem-se a atender o celular como uma questão de ética, mas que, na realidade, constitui uma regra de convivência.

Se a humanização identifica-se com um conjunto de estratégias para qualificar a atenção e a gestão do SUS, ela se estabelece, segundo a PNH (Brasil, 2004), como construção/ativação de atitudes ético- 
estético-políticas em sintonia com um projeto de corresponsabilidade e qualificação dos vínculos interprofissionais e com os usuários; então, a humanização depende essencialmente de princípios e valores interiorizados, e não tanto do puro cumprimento de normas de código ou de protocolos. Por isso é sempre possível e, às vezes até necessário, passar por cima de regras procedimentais fundado em princípios e valores e movido por atitudes de corresponsabilidade, de qualificação dos vínculos e de defesa da vida. Nesse sentido, nunca se pode passar por cima dos seus princípios, porque eles são a causa da construção/ativação de determinadas atitudes de convicção. Transigir dos seus princípios seria assumir uma a atitude antiética (Cortina, Martinez, 2005).

Referindo-se à definição já apresentada de deíticos (Rueda, 2003), será necessário utilizar a mesma para a análise deste repertório. Nesta interação discursiva, o deítico de pessoa "tu" aparece diversas vezes. A partir do momento que o sujeito não diz "eu tenho que fazer", mas "tu tens que fazer", acaba tirando a responsabilidade de si, excluindo-se indiretamente, mesmo quando fala de uma prática própria.

Partindo do pressuposto de que falar é agir, o que eles estão construindo ao falar? Os sujeitos buscam amenizar a responsabilidade individual, mas tendem a não atribuir essa responsabilidade ao grupo, pois o trabalho na equipe investigada apresentou-se de maneira fragmentada e com pouca comunicação. O uso do "tu" ao invés do "eu", ao falar das próprias práticas, sugere uma tentativa de abrandar a responsabilidade, construindo, no discurso, um sujeito implicado/desimplicado. Ao se confrontarem com a proposta de uma reflexão de segunda ordem sobre suas práticas, em relação à $\mathrm{PNH}$, demonstram dificuldade de se posicionarem enquanto sujeitos na relação com outros sujeitos na produção de saúde/cuidado.

Outro elemento importante da análise de discurso é a implicatura, ou seja, utilizar uma palavra (ou expressão) querendo referir outro significado (que não o seu próprio), o qual só pode ser entendido no contexto da enunciação (Rueda, 2003). Assim, a análise da expressão "sempre tem que passar" indica uma necessidade constante de não só passar por cima de normas e regras, como também de princípios éticos. Para eles, a consequência é uma questão técnica, e os resultados estão ligados ao uso correto dos procedimentos. Quando se referem a ter que "enjambrar", "passar por cima" dos valores, eles justificam essa atitude diante de uma possível consequência negativa através da ética da boa intenção. Mas, para assumir as consequências negativas de passar por cima de regras e procedimentos, baseado em princípios e valores, é necessário ter atitudes e convicções interiores para responsabilizar-se, e não apenas boa intenção. Ter uma atitude ética em relação às consequências seria responsabilizar-se pelo resultado, mesmo em condições precárias de ambiente, o que constituiria a ética na saúde.

Humanizar significa garantir à palavra a sua dignidade ética. Isso remete a pensar a dimensão relacional das práticas da saúde. O discurso dos profissionais demonstra preocupação com os aparelhos (tecnologias duras) e com as especialidades (tecnologias leves duras), mas, no contexto da atenção primária, as tecnologias leves desempenham um papel fundamental que transversaliza todos os outros tipos de tecnologias. Essas três formas apontam para o que Merhy (2000) chama de valises tecnológicas do profissional da saúde. Mesmo sabendo que as duas primeiras são importantes no atendimento ao usuário, a atenção básica trabalha com tecnologias relacionais de grande complexidade, pois lida com problemas do cotidiano que "dizem respeito aos modos de viver, sofrer, adoecer e morrer no mundo contemporâneo, utilizando poucos equipamentos" (Brasil, 2009, p.9).

Nessa perspectiva, Deslandes (2004) destaca a importância das tecnologias de escuta de negociações comportamentais e organizacionais, e Teixeira, 2003, aponta para as tecnologias de conversa, onde as redes de serviços de saúde passariam a ser tratadas como redes de conversações, propondo o acolhimento dialogado, ou seja, uma técnica de conversa que ajuda a interpretar as necessidades do usuário a fim de satisfazê-las. Esse espaço relacional, que pode ser criado com o acolhimento dialogado, permite que o profissional de saúde entenda, de maneira mais clara, as necessidades reais de cada usuário, pois este relata seu modo de levar a vida, assim como as dificuldades enfrentadas no seu dia a dia. A PNH traz, como uma de suas diretrizes, a implementação de um sistema de comunicação que amplie o compromisso social dos trabalhadores de saúde (Brasil, 2004). Dessa forma, humanização implica uma mudança cultural que aponta para uma mudança ética, a qual pressupõe a defesa da vida.

A proposta da humanização (Brasil, 2004) e as discussões sobre o seu embasamento teórico insistem que ela não se identifica com a atitude de bondade, mas configura-se como respeito aos direitos do 
usuário, alcançado através da construção coletiva, num processo de cogestão e corresponsabilidade dos usuários e profissionais (Rios, 2009; Oliveira, Collet, Viera, 2006). Atendimento humanizado não significa uma atitude supererogatória de caridade, mas o acolhimento do usuário em suas necessidades, entendido como algo ao qual ele tem direito. Nessa perspectiva, a humanização não depende da boa intenção do profissional, mas da satisfação das necessidades do usuário que se manifesta nas consequências. Por isso, a ética do profissional deve ser pautada pelas consequências para o alcance da resolubilidade do problema que levou o usuário a procurar a unidade.

Se o respeito aos direitos implica, igualmente, uma superação do paternalismo e um incentivo do protagonismo e da autonomia do usuário (Brasil, 2004), então a moral do profissional não pode depender da boa intenção que leva a atitudes paternalistas, mas das consequências em superar a dependência e em promover o empoderamento por meio da educação em saúde.

Os textos críticos sobre a humanização insistem também que não se pode descarregar somente nos profissionais a causa pelo mau atendimento (Simões et al., 2007; Oliveira, Collet, Viera, 2006; Gastaldo, 2005). A estratégia depende, essencialmente, de uma mudança nos processos de trabalho e de um respeito pelos direitos do próprio profissional. Ele precisa se sentir parte do processo, corresponsável na cogestão da unidade. Por isso a humanização não depende apenas da boa vontade do profissional, mas de seu comprometimento com o processo de trabalho regido pela $\mathrm{PNH}$. Neste sentido, a moral nas práticas da saúde não pode estar fundada nas boas intenções dos profissionais, mas na responsabilidade em assumir conjuntamente, como equipe multiprofissional, a gestão da unidade.

\section{Considerações finais}

Resgatando a afirmação, proposta na introdução, de que a humanização é o eixo da ética nas práticas de saúde, pois propõe movimentos instituintes de crítica e problematizações constantes acerca das práticas em saúde (Brasil, 2004), pode-se verificar que existem contradições em relação aos resultados obtidos na análise das interações discursivas dos profissionais pesquisados. Segue-se disso que, nos repertórios analisados, evidencia-se um discurso instituído e cristalizado, centrado na queixa, denunciando um conformismo com a situação do contexto de trabalho. Dessa forma, a equipe parece esperar intervenções externas que possam vir a solucionar os problemas e as carências do serviço, explicitando uma falta de protagonismo e corresponsabilidade dos sujeitos referidos.

A equipe de profissionais está implicada com a manutenção da lógica dos processos de trabalho centrados na aplicação individual de procedimentos e na intenção de dar conta da demanda, organizando-a. O que é ser ético nesse contexto? Se as condições são tão precárias, como se promovem mudanças? Pensando na perspectiva da ética da responsabilidade, mesmo em um ambiente com deficiências estruturais e organizacionais, seria necessário um movimento que mobilizasse, inicialmente, uma reflexão coletiva acerca deste quadro para, posteriormente, agenciar mudanças e transformações. Considerando a relação entre moral e ética, observou-se que os profissionais constroem um discurso moralista acerca da Humanização, analisando suas próprias práticas, ficando distante de uma visão crítica que possibilitaria uma postura ética.

\section{Colaboradores}

Os autores trabalharam juntos em todas as etapas de produção do manuscrito.

\section{Referências}

AUSTIN, J.L. Cómo hacer cosas con palabras. Barcelona: Paidós, 1998.

BRASIL. Ministério da Saúde. Secretaria de Atenção à Saúde. Política Nacional de Humanização da Atenção e Gestão do SUS. O HumanizaSUS na Atenção Básica. Brasília: Ministério da Saúde, 2009. 
BRASIL. Ministério da Saúde. Secretaria Executiva. Núcleo Técnico da Política Nacional de Humanização. Humaniza SUS: Política Nacional de Humanização: a humanização como eixo norteador das práticas de atenção e gestão em todas as instâncias do SUS. Brasília: Ministério da Saúde, 2004.

CORTINA, A.; MARTINEZ, E. Ética. São Paulo: Loyola, 2005.

DESLANDES, S.F. Análise do discurso oficial sobre humanização da assistência hospitalar. Cienc. Saude Colet., v.9, n.1, p.7-13, 2004.

GASTALDO, D. Humanização como processo conflitivo, coletivo e contextual. Interface - Comunic., Saude, Educ., v.9, n.17, p.389-406, 2005.

MERHY, E.E. Um ensaio sobre o médico e suas valises tecnológicas. Interface Comunic., Saude, Educ., v.6, n.1, p.109-16, 2000.

OLIVEIRA, B.R.G.; COLLET, N.; VIERA, C.S. A humanização na assistência à saúde. Rev. Latino-am. Enferm., v.14, n.2, p.277-84, 2006.

POTTER, J.; WETHERELL, M. Discourse and social psychology: beyond attitudes and behaviour. London: Sage Publications, 2002.

RIOS, I.C. Humanização: a essência da ação técnica e ética nas práticas de saúde. Rev. Bras. Educ. Med., v.33, n.2, p.253-61, 2009.

RUEDA, L.I. El análisis del discurso en las ciencias sociales: variedades, tradiciones y práctica. In: Análisis del discurso: manual para las ciencias sociales. Barcelona: UOC, 2003

SIMÕES, A.L.A. et al. Humanização na saúde: enfoque na atenção primária. Texto Contexto Enferm., v.16, n.3, p.439-44, 2007.

TEIXEIRA, R.R. O acolhimento num serviço de saúde entendido como uma rede de conversações. In: PINHEIRO, R.; MATTOS, R.A. (Orgs.). Construção da Integralidade: cotidiano, saberes e práticas em saúde. Rio de Janeiro: IMS/UERJ/Abrasco, 2003. p.89-111.

WEBER, M. A política como vocação. Brasília: UnB, 2003.

JUNGES, J.R. et al. La visión moral del profesional de una unidad básica de salud y la humanización. Interface - Comunic., Saude, Educ., v.15, n.38, p.755-62, jul./set. 2011.

La propuesta fue analizar la visión moral de los profesionales de una Unidad Básica de Salud (UBS) y señalar sus implicaciones para la estrategia de la humanización de asistencia. Se trata de un estudio exploratorio con enfoque cualitativo. Los datos fueron colectados en una UBS e interpretados por el análisis del discurso. Los profesionales identifican la moral como tener buenas intenciones en la asistencia, siendo los resultados más una consecuencia de procedimientos técnicos que una cuestión ética. Las directrices de la Política Nacional de Humanización proponen la coresponsabilidad y la cogestión de los profesionales, gestores y usuarios, para lograr sus objetivos de la humanización en la prestación de y de la excelencia en la prestación de los servicios de salud. La humanización corresponde a la resolución de los derechos de los usuarios; la ética de lo profesional se debe basar en los resultados, con la identificación de su responsabilidad.

Palabras clave: Ética. Moral. Atención Primaria. Humanización de la asistencia. Responsabilidad social. 